I have had the privilege of working with Chef Kusuma Cooray for more than twenty-five years. I have admired her as she shared her love of the cuisine of her native Sri Lanka with students and showed them how to blend the traditional tastes of South Asia into modern, multicultural culinary treats. Her first two cookbooks extend this knowledge to the home cook, and I eagerly have sought to learn how to at least approximate the goodness I had experienced at her table. Yet there seemed to be a missing piece. Now, in this third cookbook, Chef Cooray completes the puzzle and highlights the importance of accompaniments in creating a complete dish.

An accompaniment may sound like something that simply tags along, a little something extra to put on the plate. The notion is far from the truth. The reality is that the various chutneys, relishes, pickles, sambals, and preserves enhance and complement the other items on the plate. Sometimes they enhance and strengthen a flavor. Other times they enhance or provide a contrast in taste or texture. In all cases they work in concert with the featured dish to create a more complex, more enjoyable dining experience. Change the accompaniment and you change the experience.

I remember the conversations my wife and I would have after one of Chef Cooray's fabulous meals, and they were often as much about the delicious accompaniment as the rest of the plate. This third cookbook will help readers understand not just how to prepare these various accompaniments but more importantly how to use them, how to integrate them with the meal, how to adapt the spices and the tastes, and, in Chef Cooray's words, how to take the main dish from ordinary to heavenly. Enjoy!

\section{John Morton}

Vice President for Community Colleges, University of Hawai'i
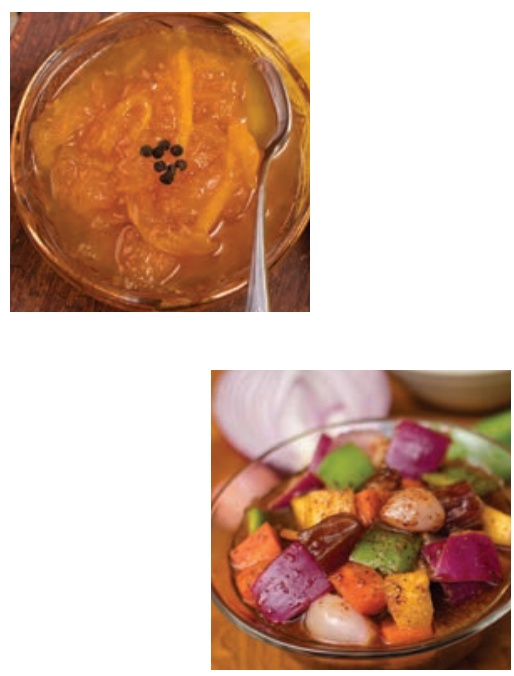
